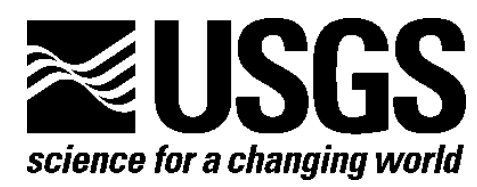

\title{
Digitized Data from Ground Geophysical Surveys in Afghanistan: A Website for Distribution of Data
}

By Sarah W. Polster and Benjamin J. Drenth

Open-File Report 2011-1270

U.S. Department of the Interior

U.S. Geological Survey 


\section{U.S. Department of the Interior \\ KEN SALAZAR, Secretary}

\section{U.S. Geological Survey \\ Marcia K. McNutt, Director}

U.S. Geological Survey, Reston, Virginia: 2011

For product and ordering information:

World Wide Web: http://www.usgs.gov/pubprod

Telephone: 1-888-ASK-USGS

For more information on the USGS-the Federal source for science about the Earth,

its natural and living resources, natural hazards, and the environment:

World Wide Web: http://www.usgs.gov

Telephone: 1-888-ASK-USGS

Suggested citation:

Polster, S.W., and Drenth, B.J., 2011, Digitized data from ground geophysical surveys in Afghanistan: A website for distribution of data: U.S. Geological Survey Open-File Report 2011-1270, 18 p.

Any use of trade, product, or firm names is for descriptive purposes only and does not imply endorsement by the U.S. Government.

Although this report is in the public domain, permission must be secured from the individual copyright owners to reproduce any copyrighted material contained within this report. 


\section{Contents}

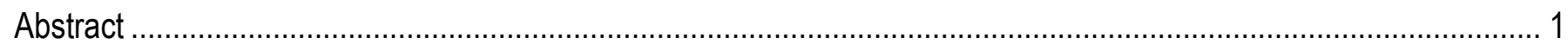

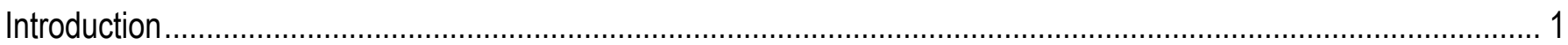

History of the Data

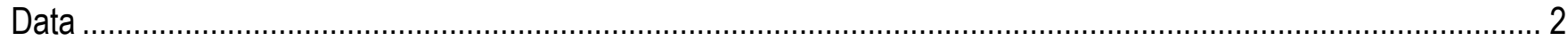

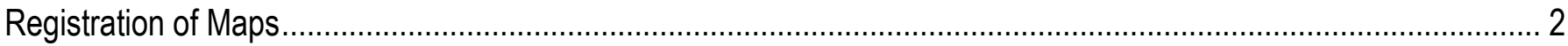

Summary

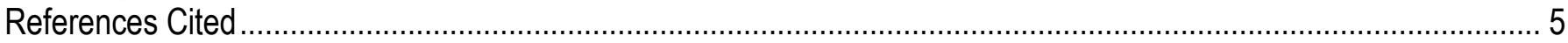

\section{Figures}

Figure 1. Index map of Afghanistan in shaded-elevation showing locations of study areas................................... 6

Figure 2. Vertical component of magnetic field in Oruzgan area including profile locations with units in $\mathrm{nT}$............ 7

Figure 3. Vertical component of magnetic field in Zarkashan area including profile locations with units in $\mathrm{nT}$.......... 8

Figure 4. Vertical component of magnetic field in Darainoor and Kalay-Asad study areas including profile

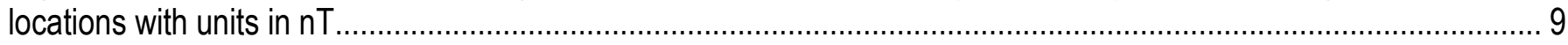

Figure 5. Total magnetic field anomaly map of Oruzgan area including profile locations with units in $\mathrm{nT}$............... 10

Figure 6. Total magnetic field anomaly map of Zarkashan area including profile locations with units in $\mathrm{nT}$............ 11

Figure 7. Total magnetic field anomaly of Darainoor and Kalay-Asad ore fields including profiles lines with units in $\mathrm{nT}$. The two ore fields overlap, justifying combining the two regions................................................... 12

Figure 8. Chargeability map of Kalay-Asad created from stacked profile data, including profile locations with percent units. In this dataset, some profile data are missing.

Figure 9. Chargeability of Zarkashan data as created from stacked profile data, including profile locations with units in percents.

Figure 10. Chargeability of Darainoor ore field created from stacked profile data, with percent units and profile locations. In this dataset, some profile data are missing....

Figure 11. Resistivity of Zarkashan study area with profile lines with units in ohm-m ..................................... 16

Figure 12. Resistivity map of Darainoor region created from stacked profile data, with ohm-m units, and profile locations. In this dataset, some profile data are missing.....

Figure 13. Resistivity map of Kalay-Asad region created from stacked profile data, with ohm-m units, and profile locations. 


\title{
Digitized Data from Ground Geophysical Surveys in Afghanistan: A Website for Distribution of Data
}

\author{
By Sarah W. Polster and Benjamin J. Drenth
}

\begin{abstract}
This document describes the process of digitization of a 1974 report on geophysical work undertaken by Soviet geophysicists in southern and eastern Afghanistan. These data, uncovered in Afghanistan, represent magnetic and electrical ground surveys for which locations are not well defined. Due to lack of location information, these surveys were georeferenced using the cities, rivers, and surrounding geology found on the maps used to plot survey locations. A geologic map found in the Soviet report contains profile lines that correspond to the geophysical maps, allowing these data to be georeferenced. The profiles correspond to sets of resistivity, chargeabiliy, and magnetic data. Some datasets were presented as graphs and needed to be gridded into a useable image. Only the vertical component of the magnetic field was collected, so conversion to total field anomaly was necessary. The magnetic data were collected in either gammas or milliorstead, both of which required conversion to standard SI units. To be useful to modern studies, the datasets and images contained in this report have been digitized, georeferenced, and in some cases converted into computer-ready formats.
\end{abstract}

\section{Introduction}

In this Open-File Report, we release data from "Report on the results of Geophysical Investigation carried out in 1973-Beginning of 1974 for Solid Minerals" (Kleimenov and others, 1974) (Appendix 1). Magnetic and electrical ground surveys were conducted in three regions in southern Afghanistan in support of mineral deposit studies (fig. 1). We have digitized these data and processed them into a modern format.

The Oruzgan field site including a massive tungsten deposit (Kleimenov and others, 1974) is located about 300 kilometers northeast of Kandahar (fig. 1). According to the report, magnetic and electrical prospecting occurred, but no figures of the electrical data appear to have survived (Kleimenov and others, 1974; Appendix 1). Zarkashan is a known gold ore (among other mineralization) locality and under intensive investigation by the U.S. Geological Survey (USGS) (fig. 1). Electrical and magnetic data were collected in the field site, both of which have been compiled in the Soviet report and registered in this paper (Kleimenov and others, 1974; Appendix 1). The Darainoor and Kalay-Asad field sites (fig. 1) contain known copper deposits (Kleimenov and others, 1974). Magnetic and resistivity data were collected in Kalay-Asad; magnetic, resistivity, and electrical data were collected in Darainoor.

\section{History of the Data}

In 1972-74, the maps and report based on geologic, magnetic, resistivity, and chargeability data were collected from twelve localities in southern Afghanistan. During the Taliban rule of Afghanistan in the 1990s, maps were outlawed. To save the data from destruction, Afghanistan Geological Survey 
(AGS) researchers split up the maps described in this report and stored them at their homes, at great personal risk. After 2001, documents were restored to the Afghanistan Geological Survey, including those described in this report. The information reported here was reassembled from the separate maps, scanned, saved to a memory stick, and carried back to the United States by a USGS employee. Here we present digital versions of the magnetic and electrical data, as well as the original report that describes the data (Kleimenov and others, 1974), as part of the Afghanistan reconstruction effort.

\section{Data}

All data in this report were collected along ground profiles. In some cases, data collected in a given area were compiled onto a geologic map or a "map of geological and geophysical prospecting results." Only datasets where a prospecting results map (hereafter referred to as a results map) was created have been successfully georeferenced and the data extracted and digitized. These locations are Zarkashan, Darainoor, Kalay-Asad, and Oruzgan (fig. 1). The results maps included profile locations associated with resistivity, chargeability (a unit of time-domain induced polarization, an electrical method) and(or) magnetic data. Several pages of the report contained stacked profiles displaying raw resistivity data and correspond to the profile locations drawn onto the results map (Kleimenov and others, 1974). All profiles were identified by profile numbers specific to each results map and the profiles are usually between 150 and 500 meters (m) long. Most profiles have corresponding stacked profiles on separate figures of magnetic and(or) electrical data on separate sheets. Unfortunately, not all the profiles were complete nor could be georeferenced. In several locations, including Jarbashi and Aynak, data were collected and stacked profiles and anomaly maps were created, but these lacked geographic, physiographic, or topographic locations, making it impossible to geographically register the data.

The magnetic data in this study are from ground surveys performed with an M-27 fluxgate magnetometer. The vertical $(Z)$ component of the magnetic field was measured. Data processing by the Soviet scientists included correcting the raw data for diurnal variations of the magnetic field and instrument drift (Kleimenov and others, 1974).

At several field sites, electrical (chargeability and resistivity) data were collected using an IKS50 type impedometer (Kleimenov and others, 1974). Chargeability, labeled $\eta_{\mathrm{k}}$ in the report and datasets, is presented as profiles and maps in dimensionless percentage units (in some maps also called percents). Resistivity, labeled $\mathrm{P}_{\mathrm{k}}$ in the Soviet report, is measured in ohm-m units.

\section{Registration of Maps}

No maps in the Soviet report contained coordinates, so creative measures were needed to register the maps. The results maps in some cases contained geographic data (for example cities and rivers), so we procured datasets of locations of settlements and rivers from Afghanistan Information Management Services (AIMS) (http://www.aims.org.af). Attempting to match the cities from the older maps to modern datasets proved problematic due to differences in spelling and(or) movement of populations - of fifteen settlements found on three geologic maps, only five settlements could be located in the modern datasets. Locating rivers (after forty years of erosion and river movement) ultimately proved too difficult and unreliable. Cities were sufficient to locate three datasets. This is a possible source of error, however; as we located the datasets closely to the modern locations of cities. We assumed that the location of cities had not changed and that cities have not grown in size. We estimate that this uncertainty contributes less than $250 \mathrm{~m}$ of location error. 
Since the results maps did not come with specified projections, we used the default datum of World Geodetic System (WGS) 1984, where the units are latitude and longitude in degrees. The data were converted into the USGS Afghan Transverse Mercator projection:

- Projection

- Central meridian

- Base latitude

- Scale factor

- Semi-major ellipsoid axis

- Eccentricity

- Horizontal datum

- Ellipsoid

$$
\begin{aligned}
& =\text { Transverse Mercator } \\
& =66 \text { degrees } \mathrm{E} \\
& =34 \text { degrees } \mathrm{N} \\
& =0.996 \\
& =6378137 \mathrm{~m} \\
& =0.08181919084 \\
& =\text { WGS } 84 \\
& =\text { WGS } 84
\end{aligned}
$$

The Zarkashan geologic map posed the largest challenge due to its lack of mapped settlements. Zarkashan is a known gold-ore deposit area that is being intensively studied by the USGS. In order to georeference this map, the Soviet geology was compared to a new USGS geologic map of the area, and an area of best fit was located (Stephen Peters, USGS, unpub. data, 2011).

Once the results maps were registered, we created ESRI shapefiles (http://www.esri.com/) for the profile locations. Shapefiles of the magnetic and resistivity isolines of the geophysical maps were created based on the Soviet map profile locations. These contours were then imported into Geosoft Oasis montaj (http://www.geosoft.com/) where the data were sampled, imported into databases, and gridded using cell sizes half the distance of the average distance between profiles ( $250 \mathrm{~m}$ for Oruzgan (fig. 2), $500 \mathrm{~m}$ for Zarkashan (fig. 3), Darainoor, and Kalay-Asad (fig. 4)). Elevation data were obtained from digital elevation models and added to the databases. The definitive geomagnetic reference field (DGRF) for the area was also added to databases.

The magnetic survey in the Oruzgan region was collected in units of milliorstead (mOe) (Kleimenov and others, 1974). The data were converted to nanotesla (nT) using the relation 1 mOe equals $100 \mathrm{nT}$ (fig. 5). Total-field magnetic anomalies were calculated from the measured vertical component data of the Darainoor, Kalay-Asad, and Zarkashan (figures 6 and 7), using standard procedures (Blakely, 1995; Phillips, 2007).

Several sets of profiles were digitized by Digital Data Services (DDS) of Denver, Colorado. The selected profiles included chargeability and resistivity data from Zarkashan, Kalay-Asad, and Darainoor. The process involved digitizing the scale included on the profiles using the mapping program AutoCAD Map (http://usa.autodesk.com/), followed by digitizing the profiles. The resulting vector DXF files were converted to tabular XYZ files and imported into Microsoft Excel spreadsheets. The Excel files were uploaded into Geosoft Oasis montaj and georeferenced by entering the coordinates of the starting point and ending point of the georeferenced profiles into the database of digitized graphs. Oasis montaj then linearly interpolated the distances along the profiles. In the two cases where the profiles turn, profiles were split and interpolated in two pieces. Because the profiles are not necessarily linear in the original survey, some error is introduced in the interpolation process. However, this error is never more than 50 $\mathrm{m}$. We produced grids (of 250-m spacing) of chargeability (figs. 8-10) and resistivity (figs. 11-13) data.

\section{Summary}

In addressing and releasing this report (Kleimenov and others, 1974), we have generated data that, due to logistical and security limitations, could not be collected today. In order to be useable for modern studies, we needed to digitize, georeference, and in some cases convert data into Oasis montaj 
databases and images. This data adds to the limited catalog of geophysical data collected in Afghanistan. Modernizing the data created databases and images that can be manipulated on computers. 


\section{References Cited}

Blakely, R. J., 1995, Potential theory in gravity and magnetic applications: Cambridge University Press, $441 \mathrm{p}$.

Kleimenov, M.A., Kamaev, S.V., and Kelesnichenke, V.A., 1974, Report on the results of Geophysical Investigations carried out in 1973-beginning of 1974 for solid minerals: USSR, Ministry of Mines and Industries, Department of Geology and Mineral Studies, $81 \mathrm{p}$.

Phillips, J.D., 2007, Geosoft eXecutables (GX's) developed by the U.S. Geological Survey, version 2.0, with notes on GX development from Fortran code: U.S. Geological Survey Open-File Report 20071355. (Available online at http://pubs.usgs.gov/of/2007/1355/.)

Publishing support provided by:

Denver Publishing Service Center

For more information concerning this publication, contact:

Center Director, USGS Crustal Geophysics and Geochemistry Science Center

Box 25046, Mail Stop 964

Denver, CO 80225

(303) 236-1312

Or visit the Crustal Geophysics and Geochemistry Science Center Web site at: http://crustal.usgs.gov/ 


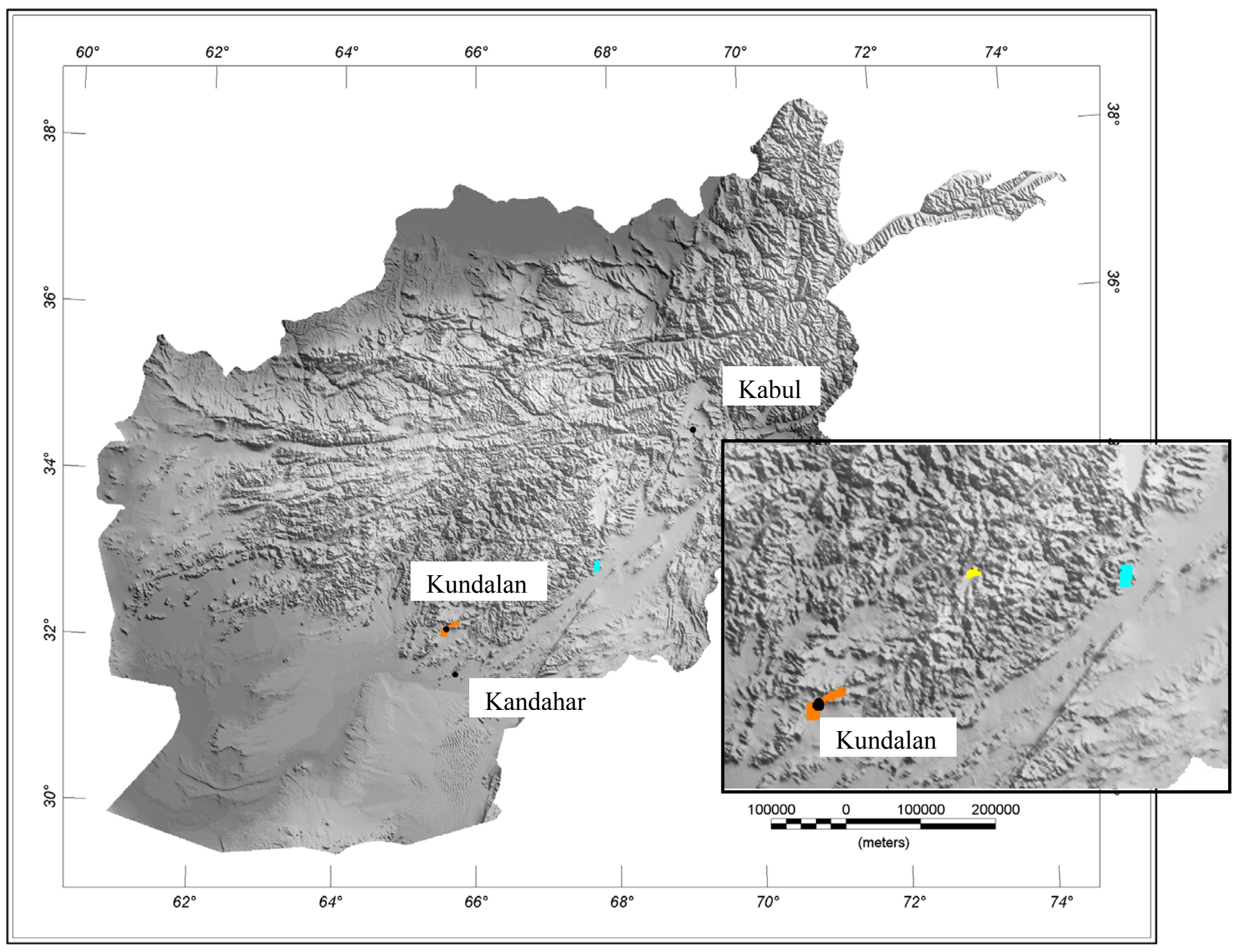

Figure 1. Index map of Afghanistan in shaded-elevation (publically avaliable Shuttle Radar Topography Mission elevation data) showing locations of study areas. The insert enlarges the study areas: orange represents the Darainoor and Kalay-Asad ore fields, blue represents the Zarkashan study area and yellow represents the Oruzgan study area. Map is projected into Afghan Transverse Mercator projection. 


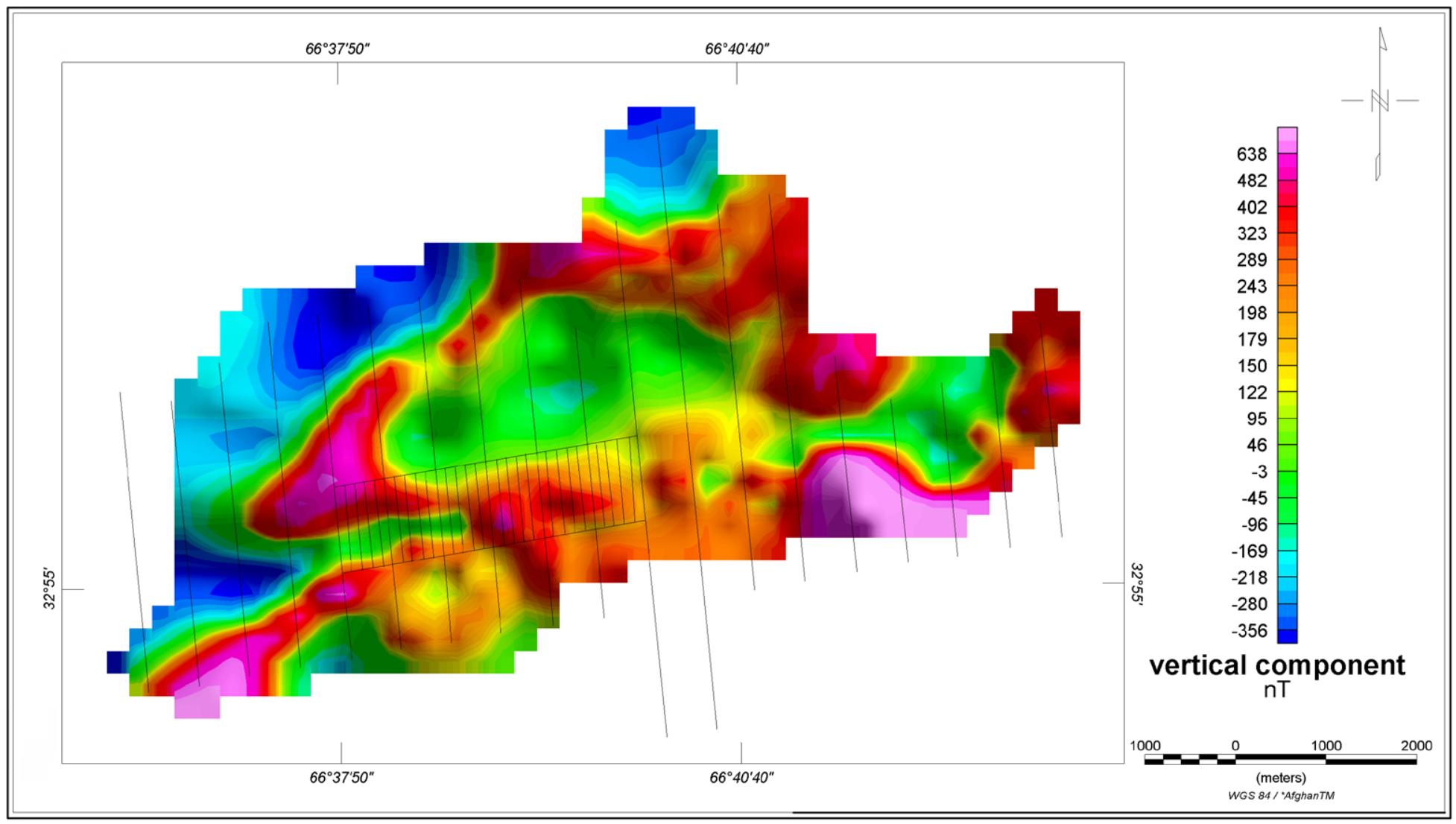

Figure 2. Vertical component of magnetic field in Oruzgan area including profile locations (black lines) with units in $\mathrm{nT}$. (nT, nanotesla) 


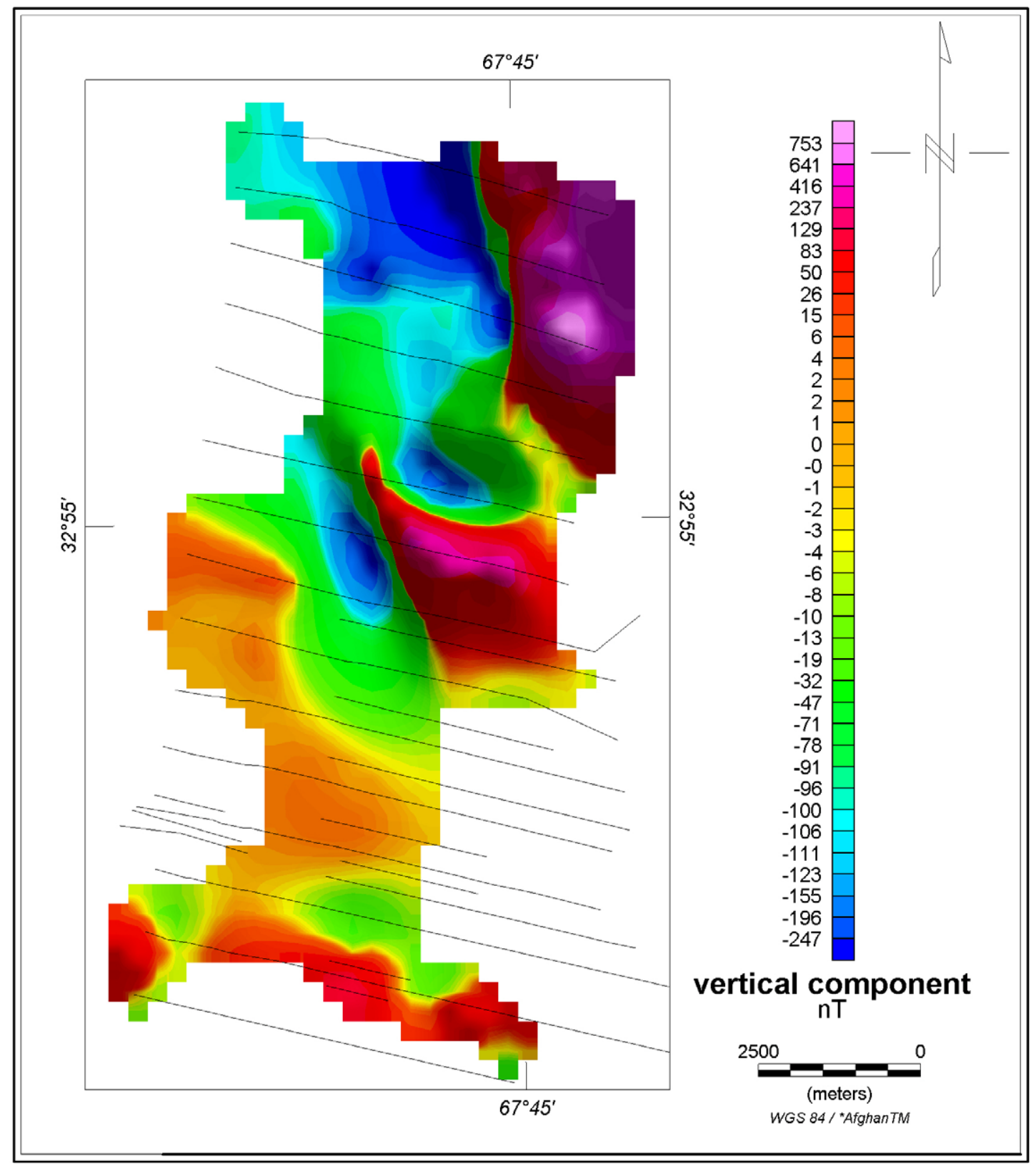

Figure 3. Vertical component of magnetic field in Zarkashan area including profile locations (black lines) with units in $\mathrm{nT}$. (nT, nanotesla) 


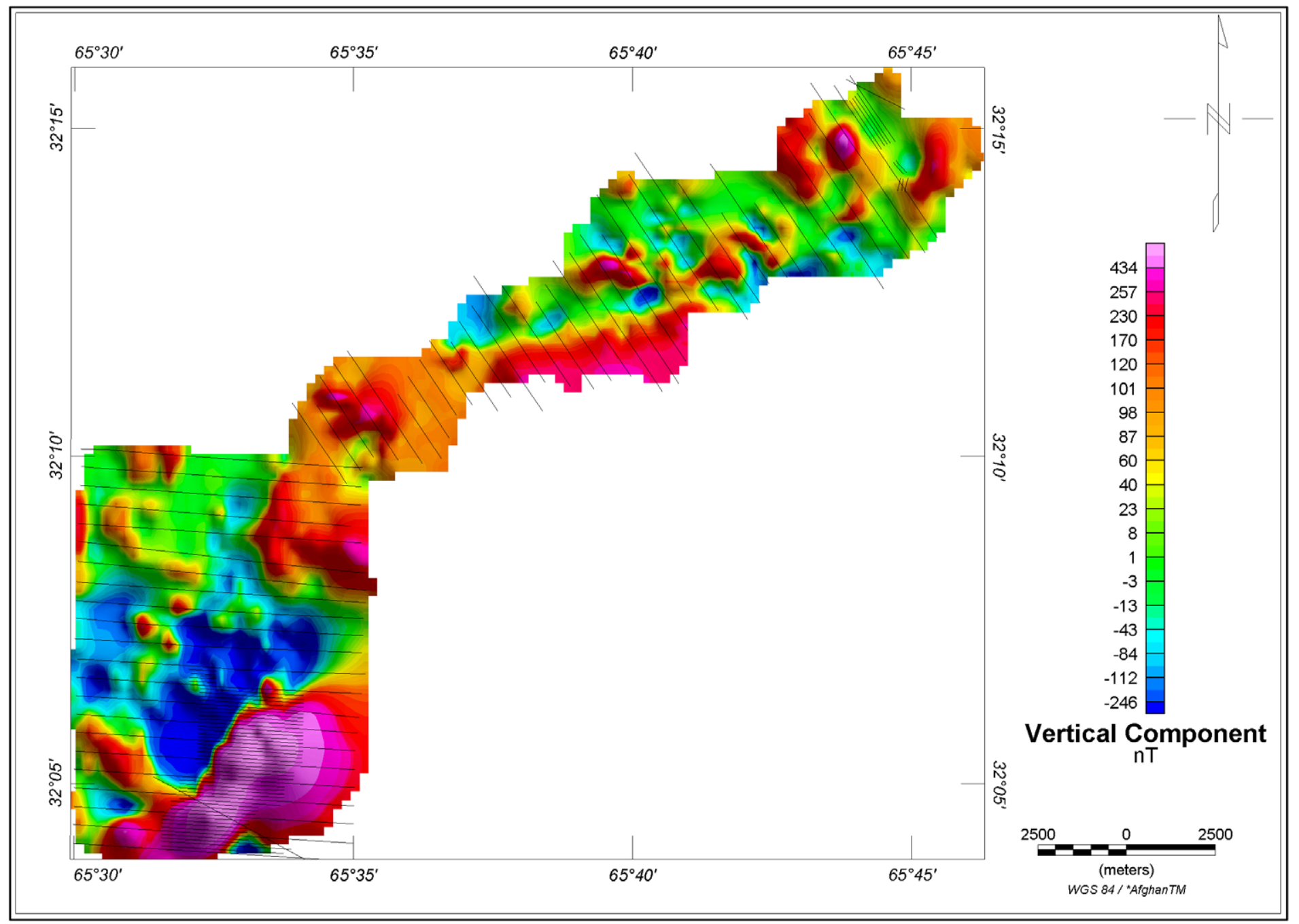

Figure 4. Vertical component of magnetic field in Darainoor and Kalay-Asad study areas including profile locations (black lines) with units in $\mathrm{nT}$. (nT, nanotesla) 


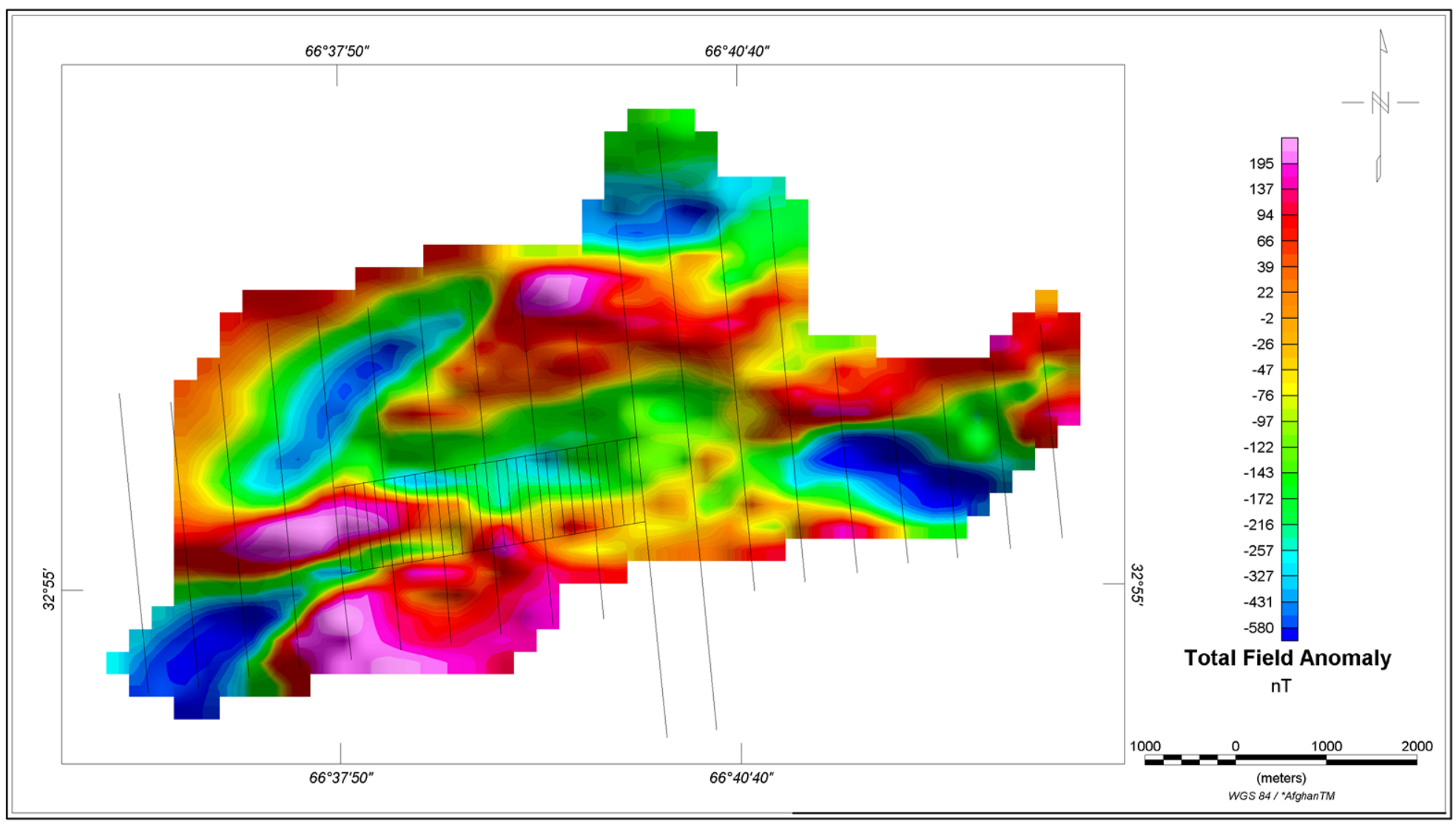

Figure 5. Total magnetic field anomaly map of Oruzgan area including profile locations (black lines) with units in $\mathrm{nT}$. (nT, nanotesla) 


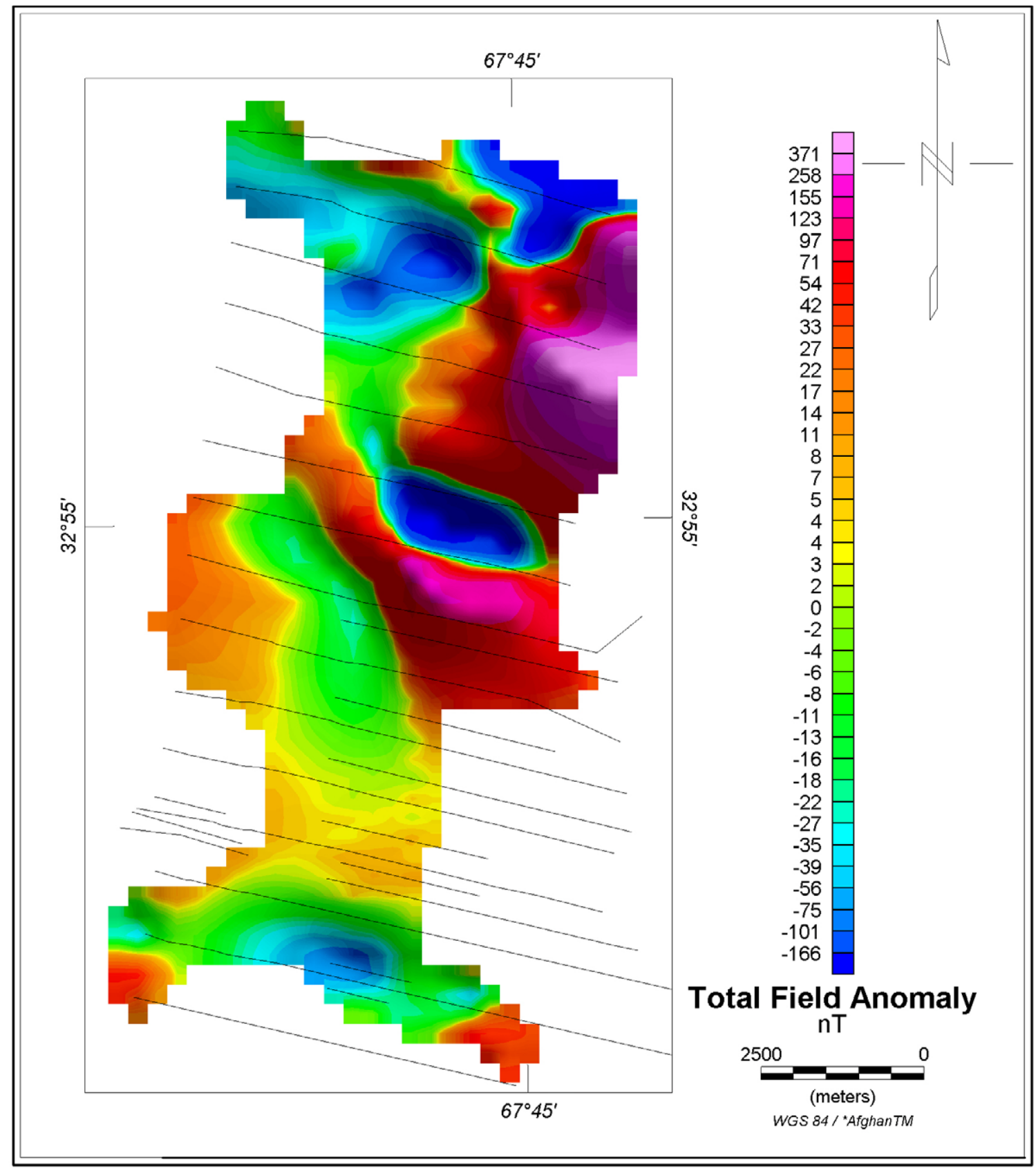

Figure 6. Total magnetic field anomaly map of Zarkashan area including profile locations (black lines) with units in nT. (nT, nanotesla) 


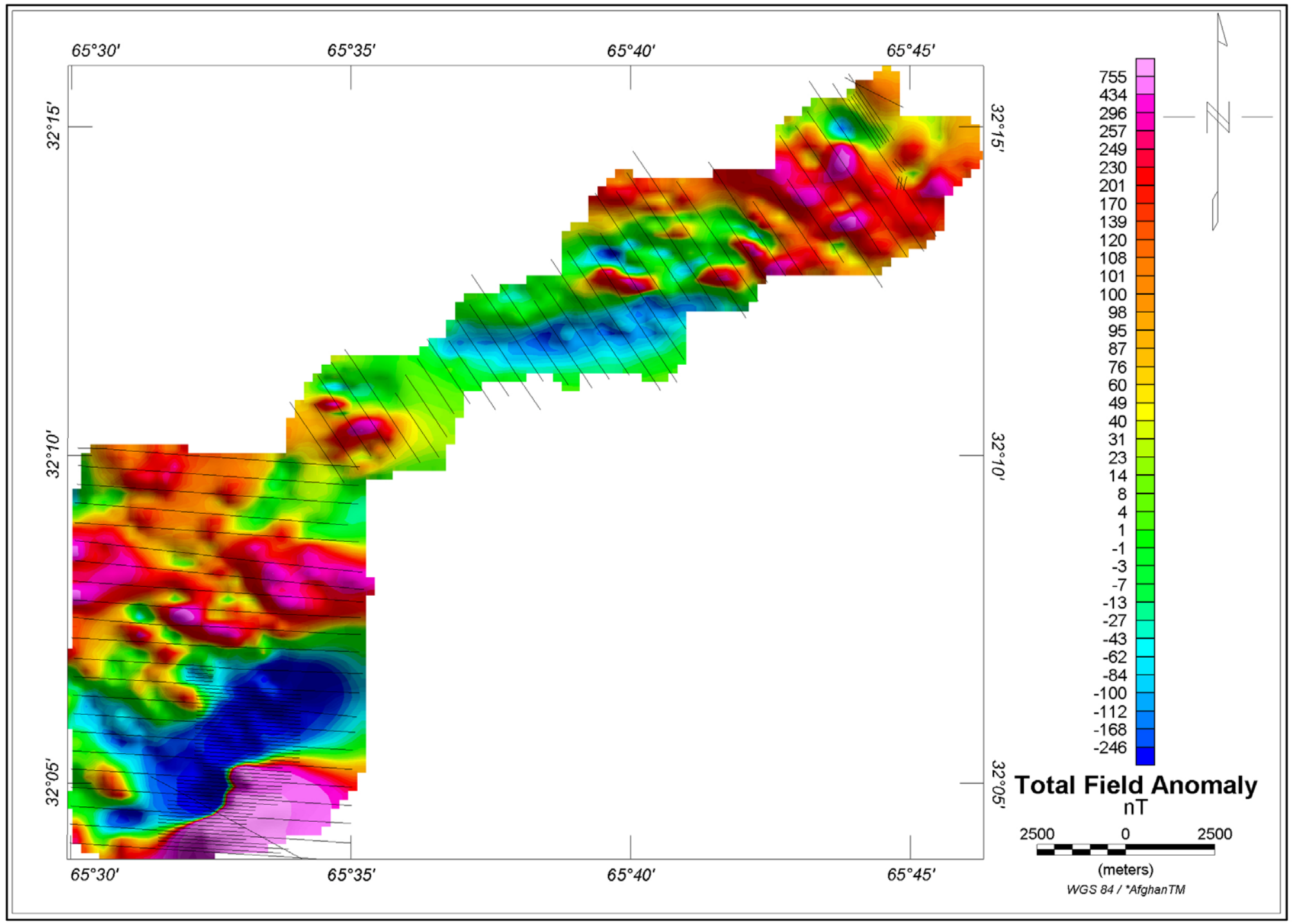

Figure 7. Total magnetic field anomaly of Darainoor and Kalay-Asad ore fields including profiles lines (black lines) with units in $\mathrm{nT}$. The two ore fields overlap, justifying combining the two regions. (nT, nanotesla) 


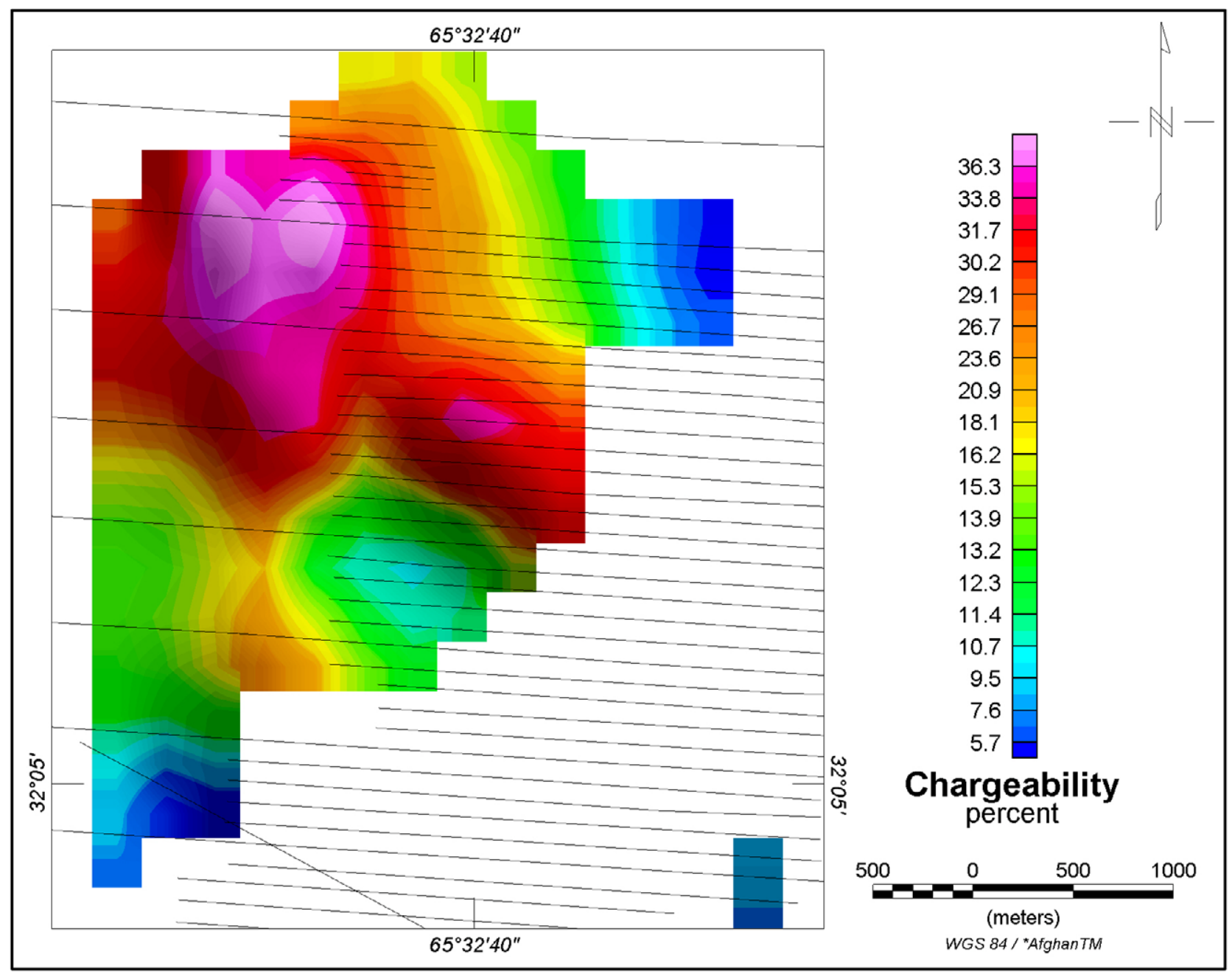

Figure 8. Chargeability map of Kalay-Asad created from stacked profile data, including profile locations (black lines) with percent units. In this dataset, some profile data are missing. 


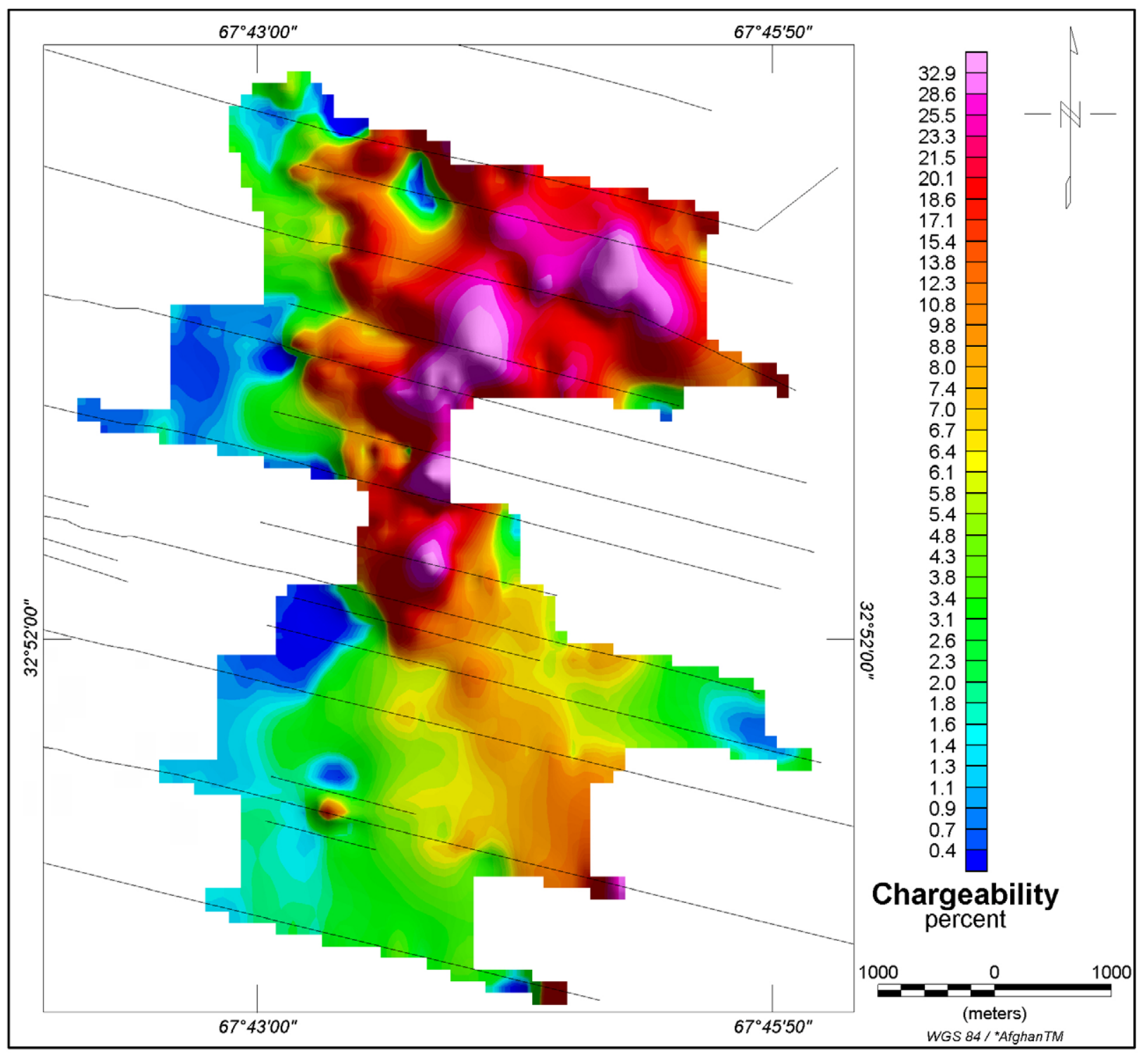

Figure 9. Chargeability of Zarkashan data as created from stacked profile data, including profile locations (black lines) with units in percents. 


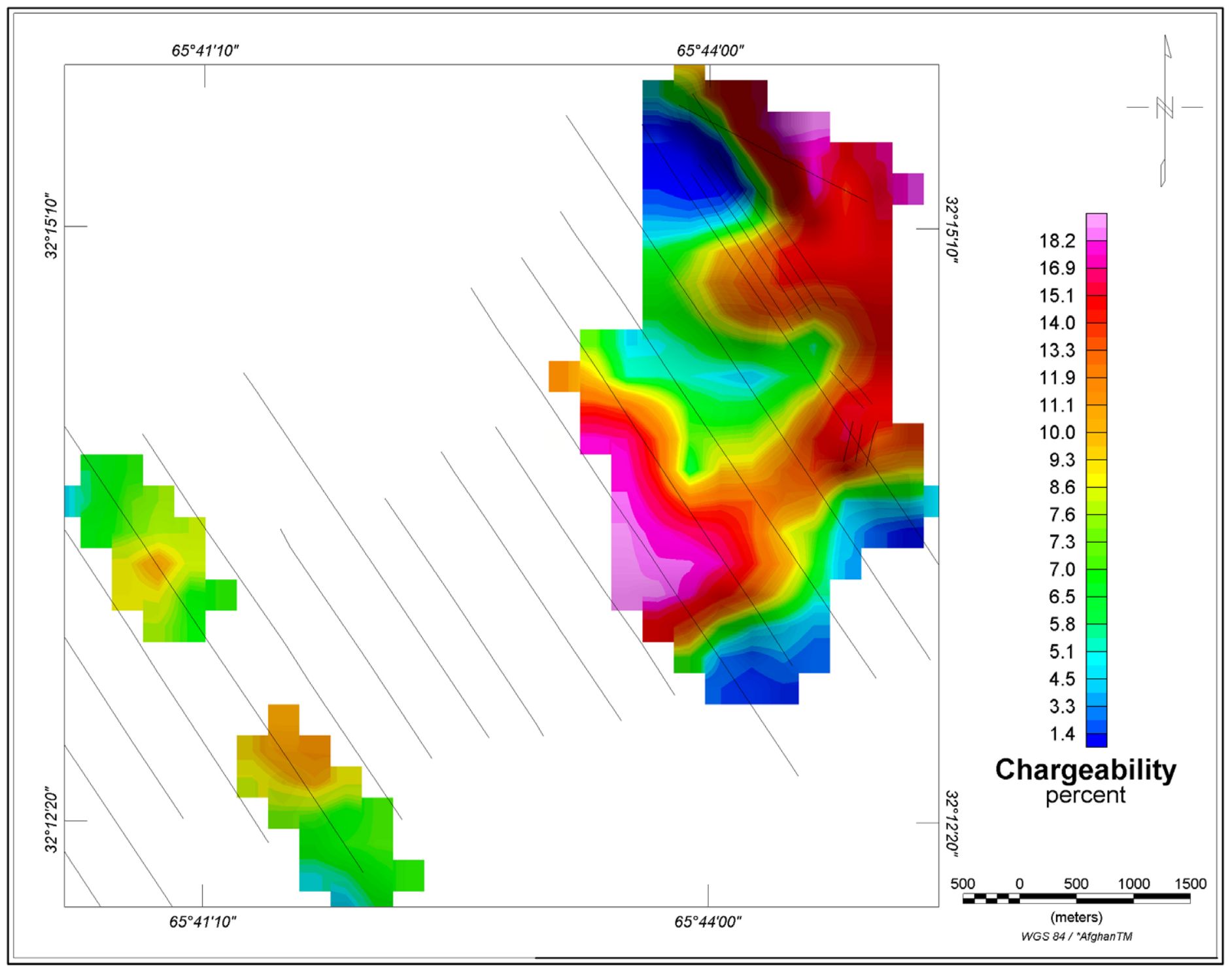

Figure 10. Chargeability of Darainoor ore field created from stacked profile data, with percent units and profile locations (black lines). In this dataset, some profile data are missing. 


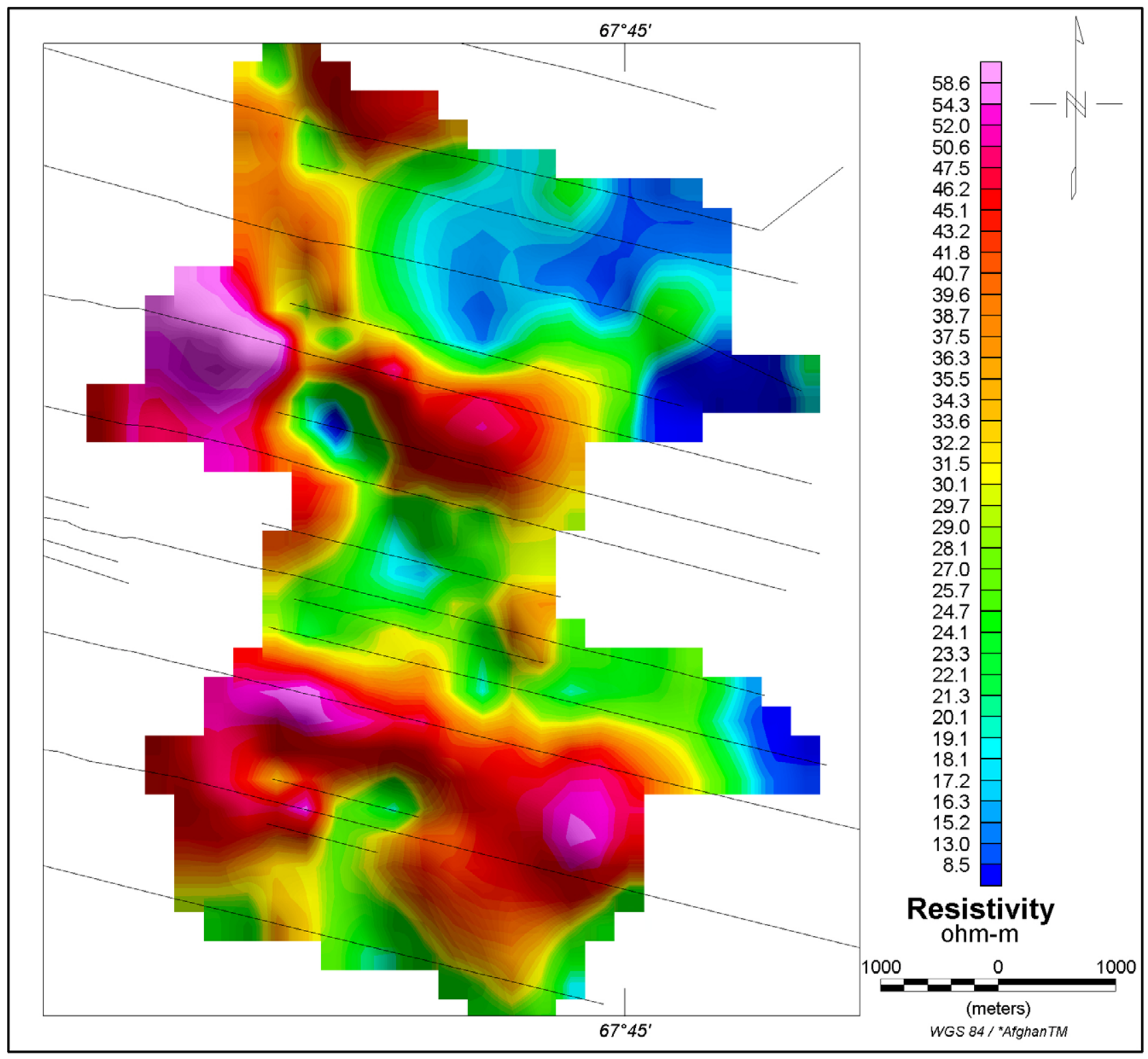

Figure 11. Resistivity of Zarkashan study area with profile lines (black lines) with units in ohm-m. (ohm-m, ohmmeters) 


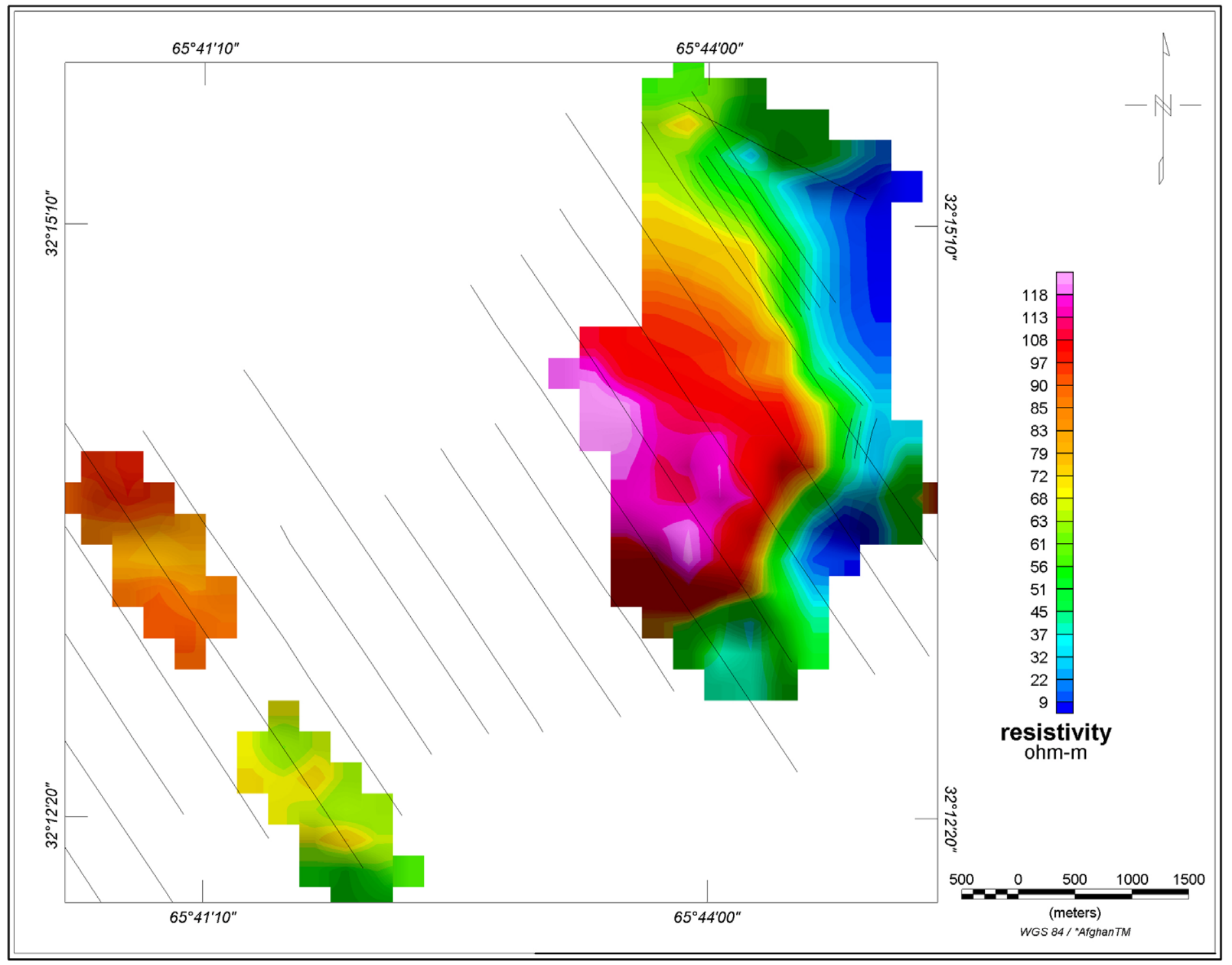

Figure 12. Resistivity map of Darainoor region created from stacked profile data, with ohm-m units, and profile locations (black lines). In this dataset, some profile data are missing. (ohm-m, ohm-meters) 


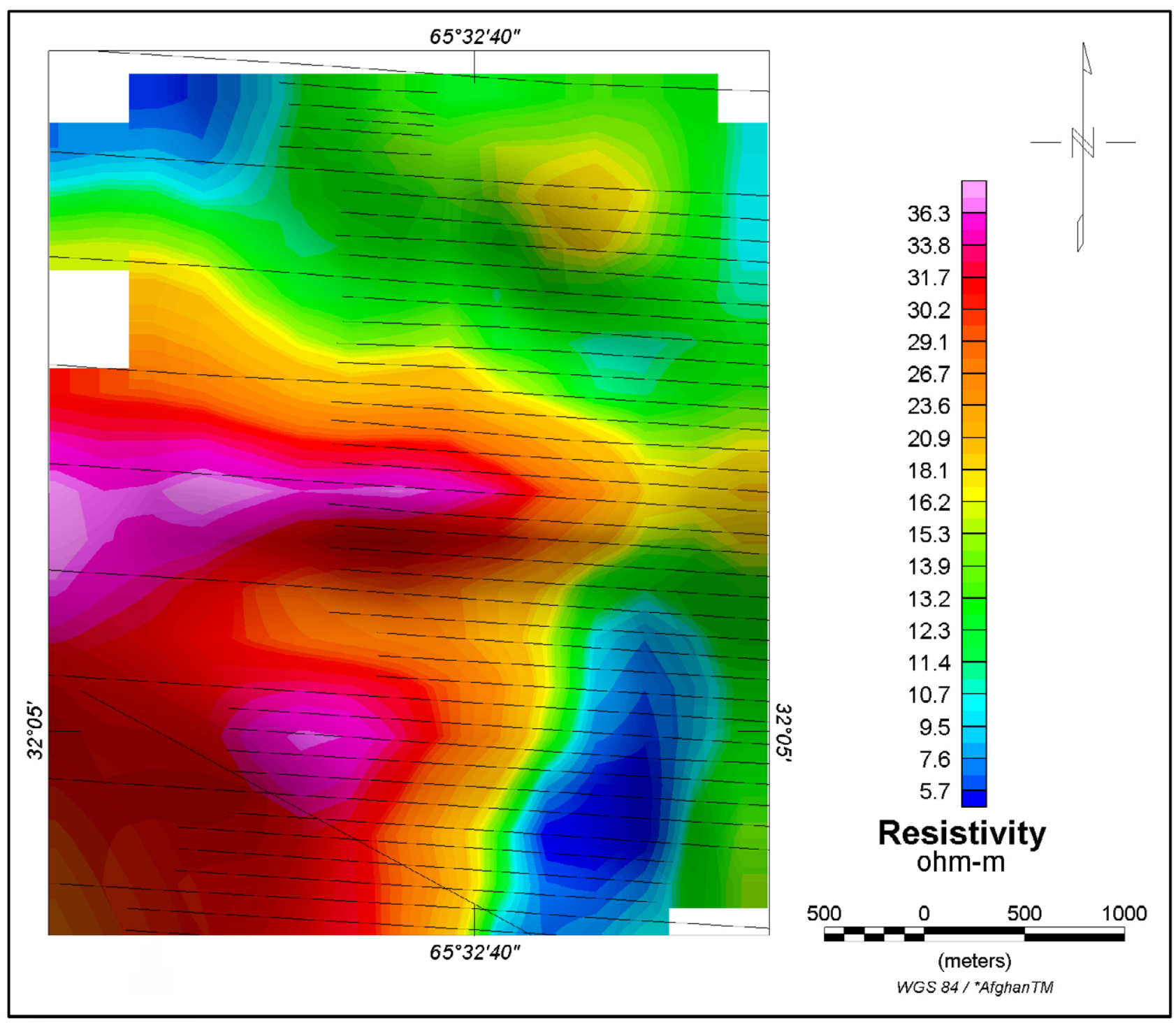

Figure 13. Resistivity map of Kalay-Asad region created from stacked profile data, with ohm-m units, and profile locations (black lines). (ohm-m, ohm-meters) 